D) Check for updates

Cite this as: $B M J 2021 ; 372: m 4945$ http://dx.doi.org/10.1136/bmj.m4945 Published: 18 January 2021

\section{Hyperglycaemia in acute coronary syndromes: summary of NICE guidance}

Clarification-This NICE guideline summary (BMJ 2011;343:d6646, doi:10.1136/bmj.d6646) has now been superseded by a summary of updated guidance at www.bmj.com/content/371/bmj.m476o. 